\title{
Food allergy to the grain-containing formula in an infant: a case report
}

\begin{abstract}
Anaphylaxis is an acute and potentially fatal allergic reaction which occurs in people with genetic susceptibility and following exposure to allergen substance through contact, inhalational or oral routes. Anaphylaxis to food stuff is the leading known factors for incidence the allergic reaction in children who are treated in emergency department. Among them wheat as an important source of food is the most common cause for incidence of anaphylaxis in children. In this report, an infant with the age of 6months old who has developed to symptoms of anaphylaxis and experienced two episode of anaphylaxis from 5 months of age following ingestion of the formula contain wheat was introduced. Skin Prick Test demonstrated that the patient had severe sensitivity to wheat and casein, and mild sensitivity to peanut and fish. There was not any history of asthma and eczema in the patient and his/her family. Patient did not receive medication therapy. In addition, with regard to lack of vaccine for prevention to disease, the cereals-free and wheat-free diets only were considered for patient.
\end{abstract}

Keywords: food allergy, grain, infant, skin prick test
Volume 4 Issue 4 - 2016

\author{
Sahar Jafari Karegar,' Roghiyeh Sattari,' \\ Esmaeil Hajinasrollah ${ }^{2}$ \\ 'Department of Nutrition Science, Urmia University of Medical \\ Science, Iran \\ ${ }^{2}$ Loghman Medical Center, Shahid Beheshti University of Medical \\ Sciences, Iran
}

\begin{abstract}
Correspondence: Esmail Hajinasrollah, Loghman Medica Center, Shahid Beheshti University of Medical Sciences, Tehran, Iran, Email iraniandiet.team@gmail.com
\end{abstract}

Received: May 13,2016 | Published: June 02, 2016

\section{Introduction}

According to the studied population, there are different causes of anaphylaxis in children. Generally, anaphylaxis in hospital is result from medications and latex, but the food allergy is the most common cause of allergy out of the hospital. ${ }^{1}$ In the west countries, allergy to peanut is the most important cause of anaphylaxis due to foods. The main pathologic manifestations in this fatal anaphylaxis include lung hyperinflation, edema and inter-alveolar bleeding, congestion the internal organs, larynx edema, hives, angioedema, and acute hypotension. ${ }^{1}$

The most foods which produce anaphylaxis are peanut, almond, shell, milk and egg. With onset of disease, patient may experience the itching around the mouth and face, sense of warming, weakness and fear and then he/she may develop to flashing, hives, angioedema, mouth itching, choking, dry cough, hoarseness, eye itching, rhinocongestion, sneezing, dyspnea, deep cough and wheezing. ${ }^{2}$ Cereal is one of the main six foods which produce $90 \%$ of food allergy in children. ${ }^{3}$ Cereal in the early age of life is added to the food of infant. 5- Gliadine is the main allergen in wheat. Gliadine is a monomer protein with molecular weight between $30-40 \mathrm{kD}$ and it contains $30 \%$ of the wheat protein. ${ }^{4}$ Recently, Herzinger et al., ${ }^{5}$ has reported a case of anaphylaxis (generalized hives, angioedema and lack of consciousness) in a 59years old man who has drunk beer. The authors indicated the wheat in the beer. ${ }^{5}$ Matsotou et al., ${ }^{6}$ reported a generalized hives attack and angioedema in one young boy who had eaten rice biscuit contained wheat protein. Immunoblot analysis demonstrated that that boy had eaten 0.26 and $1.13 \mu \mathrm{g}$ wheat. ${ }^{6}$

\section{Case report}

The patient is a 6months of age infant who developed to lip inflammation and cyanosis, wheezing and respiratory distress, severe and generalized hives by eating the soup including noodles, potato, carrot, lamb meat and wheat grains when he was 5months of age. After he referred to emergency department, he was treated by intramuscular epinephrine injection, normal saline and syrup of hydroxyzin. At the age of seven months, he developed to the above mentioned symptoms by taking the bread and again he was treated in the emergency room. After referring to the allergist, he was tested by Skin Prick Test and its result was as follow: severe sensitivity to cereal and wheat, mild sensitivity to peanut and fish. There was not any history of asthma and eczema in patient and his family. Skin Prick Test is a standard and accurate method for evaluating the allergy type 1 (by $\operatorname{IgE}$ mediator) in which specific $\operatorname{IgE}$ is measured against various allergens in vivo. In this method which is performed by positive and negative control, one drop of standard purified and concentrated extract of allergen is placed on the skin and a skin scratch without bleeding is produced by lancet or special needle. After 15 minutes, the resulted reaction which is as flare and wheal is measured by ruler. The size of this inflammated spot is compared to the spot in the negative control. The inflammated spot (wheals) $>3 \mathrm{~mm}$ than the dense area due to negative control as well as the flare area $>10 \mathrm{~mm}$ than flare due to negative control was referred as positive test.

\section{Discussion and conclusion}

The total incidence of anaphylaxis in USA is 30 per 100.000 people and it is considered approximately 81000 individuals per year; however, there is not exact statistics from people with anaphylaxis in Iran. ${ }^{7,8}$ The most common symptom of allergy is skin allergy which has been observed in more than $90 \%$ of cases. The gastrointestinal symptoms and shock are seen in $30 \%$ and $10 \%$ of cases, respectively. Fast incidence of the anaphylactic reactions indicates the more severe and serious allergic reaction. ${ }^{9}$ The diagnosis of anaphylaxis is clear due to the acute and rapid trend of this disorder. As anaphylaxis due to food is potentially fatal, it is essential to determine the food stuff which produces the allergy. ${ }^{10}$ One diagnostic ways for food allergy is skin test which should be performed by precautions. The golden standard for diagnosis of food allergy is oral challenge test which is 
performed after skin prick test and patient is exposed to the sensitive food stuff by skin test. ${ }^{11}$ As the reaction to cereal and wheat was positive in the skin test for this patient and he developed to severe anaphylactic symptoms after taking the foods contain cereal and wheat, so this test was diagnostic test for patient and it was avoided the oral challenge test which is the golden standard for diagnosis of food allergy. ${ }^{12}$

The severity of food allergies usually is decreased with increasing age and sometimes the reaction to the food stuff is negative in the skin test and patient can eat that food gradually. ${ }^{13}$ Patients who have developed to fatal reactions should eat that food carefully for their lifetime. ${ }^{14}$ Patients who developed to anaphylactic reactions should be educated about avoidance to allergens. They should read the label of the foods. Also, they should be educated about the early diagnosis of the symptoms of anaphylactic shock and rapid use of emergency medications. $^{15}$

\section{Acknowledgements}

Special thanks to close cooperation of the family of patient for adequate information that they provided to the authors.

\section{Conflict of interest}

Author declares that there is no conflict of interest.

\section{References}

1. Kemp SF, Lockey RF. Anaphylaxis: a review of causes and mechanisms J Allergy Clin Immunol. 2002;110(3):341-348.

2. Yunginger JW, Sweeney KG, Sturner WQ, et al. Fatal food-induced anaphylaxis. JAMA. 1988;260(10):1450-1452.

3. Lantner RR, Espiritu BR, Zumerchik P, et al. Anaphylaxis following ingestion of a psyllium-containing cereal. JAMA. 1990;264(19):2534-2536.

4. Palosuo K, Alenius H, Varjonen E, et al. A novel wheat gliadin as a cause of exercise-induced anaphylaxis. J Allergy Clin Immunol. 1999;103(5):912-917.
5. Herzinger T, Kick G, Ludolph-Hauser D, et al. Anaphylaxis to wheat beer. Ann Allergy Asthma Immunol. 2004;92(6):673-675.

6. Matsumoto T, Miyazaki T. Systemic urticaria in an infant after ingestion of processed food that contained a trace quantity of wheat. Ann Allergy Asthma Immunol. 2004;93(1):98-100.

7. Yocum MW, Butterfield JH, Klein JS, et al. Epidemiology of anaphylaxis in Olmsted County: a population-based study. J Allergy Clin Immunol. 1999;104(2):452-456.

8. Teymourpour P, Pourpak Z, Fazlollahi MR, et al. Cow's Milk Anaphylaxis in Children First Report of Iranian Food Allergy Registry. Iran J Allergy Asthma Immunol. 2012;11(1):29-36.

9. Asher MI, Montefort S, Björkstén B, et al. Worldwide time trends in the prevalence of symptoms of asthma, allergic rhinoconjunctivitis, and eczema in childhood: ISAAC Phases One and Three repeat multicounty cross-sectional surveys. Lancet. 2006;368(9537):733-743.

10. Brown S, Mullins R, Gold M. Anaphylaxis: diagnosis and management Med J Aust. 2006;185(5):283-289.

11. Goldman A, Anderson D, Sellers W, et al. Milk allergy I. Oral challenge with milk and isolated milk proteins in allergic children. Pediatrics. 1963;32(3):425-443.

12. Sicherer SH, Sampson HA. Food allergy. J Allergy Clin Immunol. 2010;125(2):S116-S125.

13. Sampson HA. Update on food allergy. J Allergy Clin Immunol. 2004;113(5):805-819.

14. Bock SA, Muñoz-Furlong A, Sampson HA. Fatalities due to anaphylactic reactions to foods. Journal of Allergy and Clinical Immunology. 2001;107(1):191-193.

15. Sampson HA, Muñoz-Furlong A, Campbell RL, et al. Second symposium on the definition and management of anaphylaxis: summary report-Second National Institute of Allergy and Infectious Disease/Food Allergy and Anaphylaxis Network symposium. J Allergy Clin Immunol. 2006;117(2):391-397. 